\title{
company news
}

Eriez Magnetics (Erie, Pa) are now marketing a cryogenic high gradient magnetic separation system with a field capability of $5.0 \mathrm{~T}$. The canister dimensions are 4 inches diameter and 20 inches in length. The cryomagnet is surrounded by a magnetic return circuit to promote high field uniformity. A unique feature of the system is an unusually fast switch-off (30s) and switch-on ( $-36 \mathrm{~s})$ time. The system comes complete with a $20 \mathrm{~kW}$ refrigeration unit and it is estimated that the entire system will be marketed at around $£ 300,000$.

Eriez Magnetics are also offering for sale a conventional $2.5 \mathrm{~T}$ laboratory separator unit (model EL20-4). The canister is 4 inches in diameter and 20 inches high. The field is of high uniformity. The power requirement is $144 \mathrm{~kW}$. The separator is complete with hydraulic cooling systems and power supply. The unit is designed to operate from 460 volts/3 phase/60Hz power supply but can be modified to suit user requirements. (Estimated selling price $\$ 150,000)$.

Cryogenic consultants have been commissioned to supply a linear cryogenic open gradient separation system to the Phosphate Development Corporation in South Africa for the dry processing of apatite (phosphate) ore. Each unit, with an estimated processing rate of $60 \mathrm{th}^{-1}$, costs somewhere in the region of f500, 000 . 
It is also reported that the West German Company, Humboldt Wedag have developed a cryogenic drum separator for use in both wet and dry mineral processing. The device has been developed in association with the Swiss Organisation, Sulzer (refrigeration) and with major West German Company, Siemens, Erlongen who developed the cryomagnets. No further technical details have been released at the time of publication of this Journal but early reports indicate a major technological breakthrough in magnetic separation technology. Full details of the system will be published at the 1985 International Mineral Processing Congress, Cannes. 